\title{
İș Stresi ve Güvenlik Performansı Arasındaki İlişskide Güvenlik İkliminin Düzenleyici Rolü: Sağlık Sektöründe Bir İnceleme
}

\section{The Moderator Role of Safety Climate in the Relationship between Job Stress and Safety Performance: An Investigation in the Health Sector}

\author{
Ferhat Ayyıldız ${ }^{\circledR}$, Duygu İrem Çam² ${ }^{\circledR}$
}

Yazar notu: Bu araştırmanın bir kısmı daha önce 1-2 Kasım 2019 tarihlerinde Mehmet Akif Ersoy Üniversitesi'nde düzenlenen 7. Örgütsel Davranış Kongresi'nde sunulmuştur.

${ }^{1}$ Ar. Gör., İstanbul Üniversitesi, Edebiyat Fakültesi, Psikoloji Bölümü, İstanbul, Türkiye 2Doktora Öğrencisi, İstanbul Üniversitesi, Edebiyat Fakültesi, Psikoloji Bölümü, İstanbul, Türkiye

ORCID: F.A. 0000-0003-3898-1118;

D.I.Ç. 0000-0002-6917-9745

\section{Sorumlu yazar/Corresponding author: \\ Ferhat Ayyıldız \\ İstanbul Üniversitesi, Edebiyat Fakültesi, Psikoloji Bölümü, İstanbul, Türkiye \\ E-posta/E-mail: ferhat.ayyildiz@istanbul.edu.tr \\ Başvuru/Submitted: 16.01 .2020 Revizyon Talebi/Revision Requested: 05.02.2020 \\ Son Revizyon/Last Revision Received: 14.02.2020 \\ Kabul/Accepted: 25.02 .2020 \\ Online Yayın/Published Online: 28.09 .2020}

Atıf/Citation: Ayyildiz, F. ve Cam, D. I. (2020) İş stresi ve güvenlik performansı arasındaki ilişkide güvenlik ikliminin düzenleyici rolü: Sağlık sektöründe bir inceleme. Psikoloji Çalışmaları - Studies in Psychology, 40(2): $451-475$.

https://doi.org/10.26650/SP2020-0006
ÖZ

İş stresinin görev performansıyla ilişkisi alan yazında sıklıkla incelenmektedir. Ancak, can güvenliği gibi önemli çıktıları olan güvenlik performansının iş stresiyle ilişkisini ele alan çalışmaların çok daha az olduğu görülmektedir. $\mathrm{Bu}$ nedenle mevcut çalışmanın ilk amacı, iş stresi ve güvenlik performansı arasındaki ilişkinin incelenmesi olarak belirlenmiştir. Bu ilişkiyi inceleyen önceki araştırmalarda çeşitli bireysel ve durumsal faktörlerin bu ilişkiye olan etkisinin ortaya konulmasına karşın güvenlik ikliminin düzenleyici rolünün henüz incelenmediği dikkat çekmektedir. Bu doğrultuda çalışmanın bir diğer amacı, iş stresi ve güvenlik performansının alt boyutları arasındaki ilişkide durumsal bir değişken olan güvenlik ikliminin düzenleyici rolünün sınanmasıdır. Bir yandan oldukça stresli işleri barındırması, bir yandan da çalışanlardan yüksek düzeyde güvenlik performansı beklentisine sahip olunması nedeniyle mevcut araştırma sağlık sektöründeki çalışanlar ile yürütülmüştür. Bu doğrultuda araştırmanın katılımcıları İstanbul ve Kocaeli sınırları içerisinde ulaşılabilen 165 sağlık çalışanından (\%73.3 kadın, \%26.7 erkek) oluşmaktadır. Bu çalışanlar, üçü kamu hastanesi ve sekizi özel hastane olmak üzere 11 kurumun çeşitli departmanlarında ve farklı rollerde (doktor, hemşire, teknisyen, fizyoterapist ve laborant) görev yapan kişilerdir. Verilerin toplanmasında İş Stresi Değerlendirme Ölçeği, Güvenli Davranış Ölçeği ve Güvenlik İklimi Ölçeği kullanılmıştır. Korelasyon analizi sonucunda iş stresinin güvenlik performansının alt boyutları olan güvenlik uyumu ve güvenlik katılımı ile negatif yönde ve anlamlı ilişkilere sahip olduğu görülmüştür. Ayrıca iş stresi ve güvenlik katılımı arasındaki ilişkide güvenlik ikliminin düzenleyici rolü olduğu tespit edilmiştir. Buna göre düşük güvenlik iklimine sahip ortamlarda iş stresinin güvenlik katılımını artırdığı, yüksek güvenlik iklimine sahip ortamlarda ise azalttığı tespit edilmiştir. Diğer yandan, iş stresi ve güvenlik uyumu arasındaki ilişkide güvenlik ikliminin düzenleyici bir rol oynamadığı gözlenmiştir. Bu sonuçlar, alan yazındaki diğer araştırma sonuçları ile karşılaştırılmış, ölçümle ilgili ve ortamsal faktörlerin bu sonuçlar üzerindeki etkisi tartı̧̧1lmıştır.

Anahtar Kelimeler: İş stresi, güvenlik performansı, güvenlik iklimi, sağlık sektörü, düzenleyici etki 


\section{ABSTRACT}

The relationship between job stress and task performance is frequently studied in the literature. However, it is seen that there are fewer studies examining the relationship between job stress and safety performance which has important outcomes such as life safety. Therefore, the first aim of the present study was determined as examining the relationship between job stress and safety performance. Although previous studies have demonstrated the effects of various individual and situational factors on the job stress-performance relationship, it is noteworthy that the moderator role of the safety climate has not been examined yet. In this respect, another aim of the study is to investigate the moderator role of the safety climate as a situational variable in the relationships between job stress and sub-dimensions of safety performance. The present study was conducted with employees from the health sector as it contains both the most stressful jobs and high level of safety performance expectation. In this regard, the participants of the present study consisted of 165 healthcare professionals $(73.3 \%$ women, $26.7 \%$ men) reached within the borders of Istanbul and Kocaeli. These professionals work in various departments and different roles (doctors, nurses, technicians, physiotherapists, laborants) in 11 institutions including three public hospitals and eight private hospitals. Job Stressor Appraisal Scale, Safe Behavior Scale and Safety Climate Scale were used to collect data. The correlation analysis results demonstrated the negative and significant relationship between job stress and safety compliance and safety participation as sub-dimensions of safety performance. Furthermore, it was found that the relationship between job stress and safety participation was moderated by the safety climate. These results indicate that while work stress increases safety participation in a low safety climate, it decreases in a high safety climate. On the other hand, the moderator effect of safety climate was not found statistically significant in the relationship between job stress and safety compliance. These results were compared with other research results in the literature and the effects of measurement-related and environmental factors on the results were discussed.

Keywords: Job stress, safety performance, safety climate, health sector, moderator effect

\section{EXTENDED ABSTRACT}

One of the main organizational variables affected by job stress is performance (Okutan \& Tengilimoğlu, 2002). The previous studies mostly focused on task performance, but the relationship between job stress and safety performance has been less investigated. Safety performance is defined as the safety-related behaviors of individuals or safety outcomes (Christian, Bradley, Wallace, \& Burke, 2009). Neal, Griffin and Hart (2000), one of the researchers examining the structure of this type of performance, called the task-oriented part of safety performance as safety compliance and the contextual aspect of that as safety participation. Although there are inconsistent findings in the literature regarding the relationship between stress and performance, a negative effect was often found in studies conducted in the field (Muse, Harris, \& Feild, 2003). Therefore, a negative relationship between job stress and safety performance is expected in the present study.

As a reason for the inconsistent findings in the literature, the moderator role of various individual traits in this relationship was examined and the role of factors such as age (Shirom, Shechter Gilboa, Fried, \& Cooper, 2008), self-efficacy and control level (Kavanagh, 2005) was revealed. Although it has been stated that situational and environmental factors interact with individual factors in coping with stress (Parkes, 1986), the role of organizational variables 
in this relationship has not been examined yet. Based on these statements, it is expected that a safety climate which is defined by Zohar (1980) as the sum of the perceptions shared by employees about safety may affect this relationship. Furthermore, the negative effects of job stress on safety compliance and safety participation are expected to be stronger in environments with high safety climates.

\section{Method}

The present study was conducted in the health sector as it contains the most stressful jobs and attaches importance to the concept of safety. The participants consisted of 165 health professionals ( $73.3 \%$ women, $26.7 \%$ men) reached within the borders of Istanbul and Kocaeli. These professionals work in various departments and different roles (doctors, nurses, technicians, physiotherapists and laborants) in 11 institutions including three public hospitals and eight private hospitals. Data were collected by using the Job Stressor Appraisal Scale (Özalp Türetgen, Sertel Berk, Başbuğ, \& Ünsal, 2012), Safe Behavior Scale (Dursun, 2011) and Safety Climate Scale (Türen, Gökmen, Tokmak, \& Bekmezci, 2014).

\section{Results}

According to the results of the correlation analysis, job stress showed significant negative relationship with safety compliance $\left(r_{(163)}=-.38, p<.01\right)$, safety participation $\left(r_{(163)}\right.$ $=-.24, p<.01)$ and safety climate $\left(r_{(163)}=-.59, p<.01\right)$. In addition, positive and significant relationships were seen between safety climate and safety compliance $\left(r_{(163)}=.56, p<.01\right)$ and safety climate and safety participation $\left(r_{(163)}=.38, p<.01\right)$.

According to the results of hierarchical regression analysis, the moderator role of the safety climate in the relationship between job stress and safety compliance was not significant ( $\mathrm{R}^{2}$ change $=.00, B=-.12, \beta=-.05, t=-.77, p>.05$ ). On the other hand, the safety climate has a moderator effect in the relationship between job stress and safety participation $\left(\mathrm{R}^{2}\right.$ change $\left.=.04, B=-.49, \beta=-.21, t=-2.83, p<.01\right)$. When the direction of this effect is considered with slope analysis, it is seen that safety participation was negatively affected by an increase in job stress in the environments with high safety climate (simple slope = $-1.148, t=-2.686, p<.05$ ). However, it was positively affected by an increase in job stress in the environments with low safety climate (simple slope $=1.175, t=2.501, p<.05$ ).

\section{Discussion}

The previous studies in the literature have found that various stressors perceived at work have a negative impact on productivity (e.g. Wu, 2011; Yozgat, Yurtkoru, \& Bilginoğlu, 
2013) and contextual performance (e.g. Chen, 2009; Nisar \& Rasheed, 2019). However, the present study has shown that job stress has a negative relationship between both taskoriented and contextual aspects of safety performance. As considered stressors include factors that may be related to both task performance and contextual performance, such as role and workload, insecure relationships, and organizational norms and practices, it is understandable that different aspects of safety performance were negatively affected by this stress.

Although providing a high safety climate improves safety performance (Rahlin, Mustafa, \& Majid, 2016), the sources of stress in the workplace should also be regulated to maintain these positive effects. Otherwise, these factors lead to more disruptive effects and the benefits of a high safety climate are reversed. Although various benefits of organizational climate have been demonstrated (Brown \& Leigh, 1996; Fu \& Deshpande, 2014; Neal et al., 2000), the side effects on the perception of stress factors have been demonstrated for the first time in this study.

The previous studies have shown that individual variables such as emotional intelligence (Lu \& Kuo, 2016) and core self-evaluation (Yuan, Li, \& Lin, 2014) make individuals more invulnerable to stress in terms of safety performance. On the other hand, interestingly, the current study shows that the high safety climate makes individuals more vulnerable to the effects of stress on the contextual aspect of safety performance. These results indicate that inconsistent results in the literature may be based on environmental factors in studies conducted in different environments. 
Yaşamın farklı alanlarında karşımıza çıkan ve kaçınılması mümkün olmayan stres, sürekli değişen talepler nedeniyle iş yaşamında da artmış durumdadır (Ajayi, 2018). Bu durumun sağlık ve iş süreçleri üzerindeki olumsuz etkileri hem bireylere hem de örgütlere zarar vermekte ve yüksek maliyetler yaratmaktadır (Hart ve Cooper, 2001). Doğrudan hesaplamak zor olsa da, yapılan tahmin çalışmalarında yıllık sağlık bakım harcamalarının \%5 ile \%8 arasındaki kısmının ve yıllık 120.000'den fazla ölüm vakasının iş stresi ile ilişkili olduğu ve bu durumun mali değerinin 180 milyar doları aştığ sonucuna varılmıştır (Goh, Pfeffer ve Zenios, 2016). Stresin yarattığı maddi sonuçlara ek olarak işletmelerde yol açtığı mikro düzeydeki etkiler de dikkat çekicidir. Örneğin, stresin temel örgütsel değişkenler arasında yer alan çalışan performansını olumsuz yönde etkilediği bilinmektedir (Okutan ve Tengilimoğlu, 2002). Borman ve Motowidlo (1993) çal1şan performansının farklı türlerini, işin teknik kısmına doğrudan ya da dolaylı olarak katkı sağlayan davranışları ifade eden görev performansı ile örgütsel, sosyal ve psikolojik bağlamı şekillendirerek örgütsel etkinliğe katkıda bulunan davranışları ifade eden bağlamsal performans olarak belirlemiştir. Böylece çalışanların katıldı̆̆ı veya sergilediği eylemler bireysel performans olarak ele alınırken; yerine getirdikleri tüm işlerde çalışanların, müşterilerin, halkın ve çevrenin sağlığını ve güvenliğini teşvik etmek için sergiledikleri davranışlar güvenlik performansı olarak tanımlanmaktadır (Burke, Sarpy, Tesluk ve Smith-Crowe, 2002). Risk ve tehlike barındıran madencilik, yapı, sağlık ve havacılık gibi sektörlerde özellikle üzerinde durulan performans türü ise hem göreve yönelik hem de bağlamsal bir yönü bulunan güvenlik performansı olmuştur (örn., Foster ve Hoult, 2013; Sawacha, Naoum ve Fong, 1999; Singer, Lin, Falwell, Gaba ve Bakar, 2009; Singh, Sharma, Chadha ve Singh, 2019).

Fiziksel çevrede ve çalışma koşullarında yapılan ergonomik iyileştirmelere rağmen kaza oranlarının artmaya devam etmesi, kazalara yol açan faktörler arasında sosyal psikolojik yönlere odaklanılmasına neden olmuştur. Yapılan çalışmalarda gerçekleşen birçok kazanın güvensiz davranışlardan kaynaklandığı ve bu davranışların çoğu zaman kazaların tetikleyicisi olduğu görülmüştür (Dester ve Blockley, 1995). Ayrıca Siu, Phillips ve Leung $(2003,2004)$ tarafından gerçekleştirilen araştırmalarda güvenlik tutumları ile iş kazaları arasında nedensel bir ilişki olduğu tespit edilmiştir. Dolayısıyla kazaların nedenleri arasında güvenlik davranışlarının önemli bir rolü olduğu bilindiğinden, bu davranışların oluşturduğu güvenlik performansının öncülleri de belirlenmeye çalışılmıştır. Bu doğrultuda liderlik stili, örgüt iklimi (Clarke, 2013), çalışanın psikolojik durumu, 
iş çevresinin özellikleri, yönetim politika ve uygulamalarının (El-nagar, Hosny ve Askar, 2015) veya görev ekibi, iş yeri, ekipman ve materyal varlığg gibi unsurlar arasındaki etkileşimin (Gibb, Haslam, Gyi, Hide ve Duff, 2006) güvenlik performansını etkileyen değişkenler olduğu ortaya koyulmuştur. Bunlara ek olarak, güvenlik konusunun mühim olduğu alanlarda çalışanların iş güvencesinin olmamasının bir stres kaynağı olduğu, dolayısıyla bu kişilerde güvenlik bilgisini ve güvenlik politikalarına uyma motivasyonunu azalttığ1 tespit edilmiştir (Probst ve Brubaker, 2001). Ayrıca iş talepleri ve kaynaklarının motivasyonel süreçler ve sağlıktaki bozulma süreçleri aracılığıyla iş kazalarını ve yaralanmaları, olumsuz vakaları ve güvensiz davranışları etkilediği görülmüştür (Nahrgang, Morgeson ve Hofmann, 2011). Bu sonuçlar, iş stresinin güvenlik performansını etkileyebileceğini göstermektedir. Ancak alanda bu iki değişkenin ilişkisini inceleyen çalışmaların oldukça sınırlı sayıda olduğu görülmektedir (örn., Hofmann ve Stetzer, 1996). Bu sınırlılığı gidermek üzere mevcut çalışmada iş stresi ile güvenlik performansı arasındaki ilişkiyi incelemek amaçlanmıştır.

Stres ve güvenlik kavramları belirli sektörlerde diğerlerine kıyasla daha fazla önemsenmektedir. İngiltere' de en stresli işleri belirlemeye yönelik Cary Cooper (1997) tarafından yürütülen araştırmada hemşirelik, doktorluk, dişçilik ve ambulans şoförlüğü gibi sağlık sektöründeki meslekler ilk sıralarda yer almıştır (Akt., Cranwell-Ward ve Abbey, 2005). Diğer yandan, güvenlik kültürü ve iklimine yönelik çalışmaların da çoğunlukla iş sağlığı ve güvenliği açısından riskli kabul edilen sağlık (örn., Dollard ve McTernan., 2011), havacılık (örn., Gill ve Shergill, 2004) ve inşaat (örn., Siu ve diğ., 2004) gibi sektörlerde yürütüldüğü dikkat çekmektedir. Bu bulgular dikkate alınarak mevcut çalışmanın sağlık sektöründe yürütülmesine karar verilmiştir.

İş stresinin güvenlik performansı ile ilişkisinde öz benlik değerlendirmesinin (Yuan, Li ve Lin, 2014) ve duygusal zekanın (Lu ve Kuo, 2016) düzenleyici rolünün ele alınd1ğ1 görülmektedir. Stres ile performans ilişkisinde örgütsel faktörlerin de rol oynayabileceği öne sürülmüştür (Bowers, Weaver ve Morgan, 1996). Ancak söz konusu güvenlik performansı olduğunda henüz hiçbir örgütsel faktörün düzenleyici rolünün incelenmediği görülmektedir. Bu faktörlerden biri olabileceği düşünülen güvenlik iklimi çalışanlar tarafından güvenlik değerleri, normları, inançları, uygulamaları ve prosedürlerine ilişkin paylaşılan algılar olarak tanımlanmaktadır (Silva, Lima ve Baptista, 2004). İş stresinin güvenlik performansı üzerindeki olumsuz etkisi güvenlik ikliminin yüksek olduğu ortamlarda daha fazla olabilir, çünkü bu ortamlarda çalışanlardan beklenen güven- 
lik performansı da yüksektir. Örgüt iklimi güvenliği vurgulamadığında, çalışanların algıladıkları stresin olumsuz etkilerinin güvenlik performansından ziyade mevcut iklimde değer verilen unsurlara yansıması olasıdır. Bu doğrultuda çalışmanın bir diğer amacı olarak güvenlik ikliminin, iş stresi ve güvenlik performansı arasındaki ilişkide nasıl bir rol oynayacağı incelenecektir.

\section{Güvenlik Performansı ve İş Stresiyle İlişkisi}

Güvenlik performansı, bireylerin güvenlikle ilgili davranışları ya da güvenlik çıktıları üzerinden anlaşılmaktadır (Christian, Bradley, Wallace ve Burke, 2009). Bu performansın göstergesi olarak şirketteki kaza istatistikleri, çalışanların bildirimine dayalı güvenlik davranışları ile olay ve kazalarda yer alma oranı ve yönetici/amir tarafından yapılan değerlendirmeler gibi kriterler kullanılmaktadır (Yule, 2003). Yapılan bir araştırmada öz bildirime dayalı güvensiz davranışların bu kazaların en önemli belirleyicisi olduğu bildirilmiştir (Mearns, Whitaker ve Flin, 2001). Bu sonuçlara dayalı olarak mevcut çalışmada güvenlik performansı, öz bildirime dayalı güvenlik davranışları olarak ele alınmıştır.

Güvenlik performansının yapısını incelemek amacıyla Neal, Griffin ve Hart (2000) tarafından yapılan araştırmada, güvenlik performansının göreve ilişkin ve bağlamsal yönleri ortaya koyulmuştur. Buna göre, güvenlik uyumu güvenlik prosedürlerine uyma ve işlerin güvenli bir şekilde yapılması olarak tanımlanmaktadır. Ayrıca, güvenlik performansının göreve yönelik kısmını temsil etmektedir. Güvenlik katılımı ise iş arkadaşlarına yardım etme, iş yerinde güvenlik programını teşvik etme, iş yerinde güvenliği arttırmak için çaba gösterme ve inisiyatif kullanma olarak açıklanmaktadır. Aynı zamanda, güvenlik performansının bağlamsal yönünü temsil etmektedir. Mevcut çalışmada da öz bildirime dayalı güvenlik davranışları, bu ayrım kapsamında değerlendirilmiştir.

Bireylerin güvenlik performansını etkileyen çeşitli faktörler bulunmaktadır. Bu faktörleri şantiye ortamında inceleyen Sawacha ve arkadaşları (1999) tarihsel, ekonomik, psikolojik, teknik, prosedürel, örgütsel ve iş çevresi ile ilgili olmak üzere yedi başlıkta toparlamıştır. Tarihsel faktörler arasında en önemlisi yaş olarak bulunmuştur; genç çalışanlar yaşça büyük olanlara nazaran daha fazla kaza riski taşımaktadır. Bu yalnızca yaş ile ilgili değil, beraberinde gelen deneyimin de artması ile ilgilidir. Ekonomik değişkenlerden en önemlisi kaza ödemesinin yapılması olarak ortaya çıkmıştır. Kaza ödemesi yapılması, kaza oranıyla pozitif ilişki içinde bulunmuştur. $\mathrm{Bu}$ durumun aslında teşvik 
amaçlarına aykırı olduğu görülmektedir. Psikolojik değişkenler arasında en öne çıkanı ise bireyin kendi güvenliğine özen göstermesi olmuştur. Bu bireylerin güvenlik performansı da daha yüksek bulunmuştur. Teknik faktörler arasında en önemlisi tehlikeli maddelerin farkında olmaktır. Prosedürel olarak ise çalışanları güvenlik konusunda eğitmenin performansı artırdığı saptanmıştır. Güvenlik performansının en önemli yordayıcısı olan örgütsel faktörler konusunda, yöneticilerin başarılı güvenlik performansına ulaşmada katılımı ve desteği önem arz etmektedir. İş çevresi ile ilgili olarak düzenli ve iyi planlanmış çevrelerin güvenlik performansı ile pozitif ilişkiye sahip olduğu bulunmuştur (Sawacha ve ark., 1999). Bir başka çalışmada ise liderliğin de güvenlik performansında önemli olduğuna dikkat çekilmiştir (Wu, Chen ve Li, 2008). Bu doğrultuda bireylerin güvenliğe olan bağlılığını ve güvenlik davranışını artırmada liderlerin güvenlik kontrolü gerçekleştirmesi, kendilerini etkileyecek kararlara personelleri dahil etmesi ve kaynakları uygun dağıtması önerilmiştir.

İş stresi ise güvenlik sonuçlarını etkilemesi beklenen bir diğer önemli faktördür (Siu ve ark., 2003). Öncelikle iş stresinin performans üzerindeki etkilerine yönelik öne sürülen yaklaşımlara bakılırsa erken dönemdeki ilk yaklaşımda Yerkes ve Dodson (1908), uyarılma ve performans arasındaki ilişsinin ters U biçiminde olduğunu, bir diğer deyişle işteki baskının belirli bir düzeye kadar üretkenliğin artmasını sağladığını, fakat bu baskı aşırıya vardığında negatif etkilerinin ortaya çıktığını belirtmiştir. Yaygın olarak kabul edilen bir diğer görüşte ise stresin performansı olumsuz etkileyeceği düşünülmektedir (Wu, 2011). Bu olumsuz etkinin gerekçesi olarak alan yazında çeşitli açıklamalar getirilmiştir. Örneğin, stresörün yarattı̆̆ı bilgi yükünün algısal dikkati azaltmasından ötürü performansla ilişkili bilgi ve ipuçlarının göz ardı edilmesi, bireylerin tehdit edici bir talep algıladığında enerji ve zamanlarını bu stres etkenine ayırdıklarından dolayı çabalarının bölünmesi ve stresörlerin performansa etki edecek fizyolojik tepkiler doğurması bunlar arasındadır (Gilboa, Shirom, Fried ve Cooper, 2008). Farklı olarak LePine, Podsakoff ve LePine (2005), stresör türüne bağlı olarak bu etkilerin değişeceğini öne sürmüştür. Buna göre engelleyici stresörler performans üzerinde olumsuz etkiler yaratabilirken, meydan okuyucu stresörler performans üzerinde olumlu etkide bulunabilmektedir. Alan yazında sözü edilen üç ilişkiyi de destekleyen çalışmaları görmek mümkün olsa da tüm bu tutarsız bulgular stresin ölçümünde bazen stresör (örn., Liu, Song ve Wang, 2011) bazen de zorlanmaların (örn.; Jamal, 2007) temel alınmasına, diğer bir deyişle araştırmalarda kavram birliği olmamasına bağlı olarak ortaya çıkmış olabilir. Ayrı- 
ca incelenen stresör ile performans türünün ve bağlamın stres-performans ilişkisini farklılaştırmış olması da mümkündür. Çalışmaların yürütüldüğü bağlamı değerlendirdiğimizde laboratuvar araştırmaları anlık stresi değerlendirirken, alanda yürütülen araştırmalar kronik stres üzerinde durmaktadır. Gerçek çalışma ortamlarında stres ve performans arasındaki ilişkiyi inceleyen araştırmalara bakıldığında ters $U(\% 4)$ ve pozitif doğrusal (\%13) ilişki öne süren modellerin çok az desteklendiği görülmektedir (Muse, Harris ve Feild, 2003).

İş stresinin doğrudan güvenlik performansına olan etkilerini inceleyen araştırmalar ise oldukça kısıtlı kalmıştır. Bu araştırmalardan birinde Hoffmann ve Stetzer (1996), iş baskısı, iletişim ve koordinasyon problemleri gibi grup süreçlerinin ve olumsuz sosyal iklimin güvenlik performansı üzerinde etkili olan örgütsel faktörler olduğunu bulmuştur. Bir diğer araştırmada Siu ve arkadaşları (2004) anksiyete, depresyon ve iş yavaşlatma ile ölçülen zorlanmanın da güvenlik performansı üzerinde olumsuz etkileri olduğunu göstermiştir. Leung, Chan ve Yu (2012) ise fiziksel stres ve güvenli davranma arasında doğrusal; duygusal stres ve güvenli davranma arasında ters U biçiminde eğrisel bir ilişki bulmuştur. Enshassi, El-Rayyes ve Alkilani (2015) ise iş stresi ve güvenlik performansı arasında anlamlı bir ilişki bulamamıştır. Bu araştırmaların her biri gerçek çalışma ortamında yürütülmüş olsa da, daha önce de belirtildiği gibi, hem stresörlerin hem de farklı zorlanma türlerinin iş stresi olarak değerlendirilmiş olması elde edilen tutarsız bulguların gerekçesi olarak düşünülmektedir. Gerçek çalışma ortamlarında iş stresi ile performans arasında olumsuz bir ilişki olduğu önermesinin daha çok kabul görmesi göz önünde bulundurularak güvenlik performansı ile de benzer bir ilişkiye sahip olması beklenmektedir. Buna dayalı olarak Hipotez 1 şu şekilde ifade edilmiştir:

H1: İş stresi ile güvenlik performansının a) güvenlik uyumu ve b) güvenlik katılımı boyutları arasında negatif yönlü anlamlı bir ilişki vardır.

\section{Güvenlik İklimi ve Stres-Performans İlişkisindeki Rolü}

İş stresinin performans üzerinde olumsuz etkide bulunacağı öne sürülmekle birlikte, yukarıda söz edilen tutarsız bulgulara neden olabilecek bir diğer faktörün de düzenleyici değişkenler olabileceği ileri sürülmüştür. Bu etkileri incelemeye yönelik çalışmalarda yaş (Shirom, Shechter Gilboa, Fried ve Cooper, 2008), süpervizörden sağlanan sosyal destek (Schreurs, Hetty van Emmerik, Günter ve Germeys, 2012), öz etkinlik, kontrol düzeyi, belirsizlik ve eğitim verilmesi (Kavanagh, 2005) gibi faktörlerin düzenleyici 
olabildiği gösterilmiştir. İş stresi ve güvenlik performansı arasındaki ilişki özelinde ise bireysel özelliklerin rolünü inceleyen sınırlı sayıda çalışma bulunmaktadır. Bu çalışmalardan ilkinde, meydan okuyucu stresörlerin güvenlik uyumu üzerindeki ve engelleyici stresörlerin güvenlik katılımı üzerindeki negatif etkisinde bireylerin öz benlik değerlendirmelerinin tampon rol oynadığı görülmüştür (Yuan ve ark., 2014). Yapılan bir diğer çalışmada ise duygusal zekanın iş stresi ve güvenlik uyumu arasındaki ilişkide düzenleyici olduğu, duygusal zeka düşük olduğunda güvenlik uyumunun işs stresinden daha fazla olumsuz etkilendiği bulunmuştur ( $\mathrm{Lu}$ ve Kuo, 2016).

Diğer yandan, iş stresinin güvenlik performansı üzerindeki etkisini biçimlendirebilecek örgütsel değişkenler henüz ortaya konulmamıştır. Mevcut çalışmada örgütsel bir değişken olarak güvenlik ikliminin bu süreçte rol oynayabileceği düşünülmüştür. Örgüt iklimi bir işteki politikalar, uygulamalar ve prosedürler ile ödüllendirilen, desteklenen ve beklenen davranışları ifade eder (Schneider, Ehrhart ve Macey, 2011). Bir başka tanımlamada da resmi veya gayri resmi örgütsel politika, uygulama ve prosedürlerin alg1s1 olarak betimlenmiştir (Ostroff, Kinicki ve Muhammad, 2013). Örgüt iklimi, örgüt kültürüne nazaran daha fazla değişir. İklim örgüt içerisinde neler olduğunu tanımlarken, kültür neden öyle olduğuna ilişkin varsayımlara dayanır (Schein, 2000; Schneider, 2000). Örgüt kültürü, örgütlerin kişilik gibi kalıcı bir karakteri olarak tanımlanabilirken; örgüt iklimi ise belirli bir zamandaki ruh hali gibi davranışa ilişkin algılarla ilişkilidir (Australian Transport Safety Bureau, 2004).

Alan yazında ilk olarak Zohar (1980) tarafindan ortaya atılan güvenlik iklimi kavramı, örgüt ikliminin özel bir biçimidir ve güvenliğe ilişkin çalışanların paylaştıkları algıların toplamı olarak ifade edilmiştir. Güvenlik iklimini oluşturan algıların iki temel özelliği bulunmaktadır. İlk olarak, güvenlik iklimini oluşturan algılar bireyler arasında paylaşılır. İkincisi, bu algılar doğası gereği tanımlayıcı ve bilişsel olarak nitelendirilmektedir (Griffin ve Curcuruto, 2016). İşgücünün belirli bir zamandaki tutumunu ve algılarını ifade eden güvenlik iklimi, güvenlik kültürünün görünür özelliğidir. Bir başka ifadeyle, örgütün güvenlik kültürünün bir göstergesi olan güvenlik durumunun anlık görüntüsüdür (Flin, Mearns, O'Connor ve Bryden, 2000).

Güvenlik ikliminin yapısını inceleyen araştırmalarda çeşitli alt faktörlere ulaşılmıştır. Dedobbeleer ve Beland (1991) tarafindan gerçekleştirilen çalışmada iki faktör ön plana çıkmıştır; bunlar yönetimin güvenliğe bağlllığı ve çalışanların güvenliğe katılımı- 
dır. Williamson, Feyer, Cairns ve Biancotti’nin (1997) çalışmasında ise beş faktöre ulaşılmıştır; bunlar güvenlik davranışı için kişisel motivasyon, pozitif güvenlik uygulamaları, risk gerekçelendirme, kadercilik ve iyimserliktir. Kullanılan farklı ölçüm araçlarında en çok değerlendirilen boyutları belirlemek amacıyla Flin ve arkadaşları (2000) tarafından gerçekleştirilen çalışmada ise boyutlar şu şekilde belirlenmiştir: yönetimin güvenlikle ilgili tutum ve davranışlarına dair bireysel algılar, güvenlik sistemi (prosedürler, uygulamalar ve araçlar), risk almaya ilişkin tutumlar, iş baskısı ve bilgi, beceri, eğitim açısından yeterlilik.

Güvenlik iklimine ilişkin çalışmalarda çoğunlukla pozitif ve negatif güvenlik ikliminin güvenlik sonuçlarıyla ilişkisinin incelendiği görülmektedir (örn., Christian ve ark., 2009; Clarke, 2010; Griffin ve Curcuruto, 2016; Neal ve Griffin, 2006). Diğer yandan güvenlik ikliminin çeşitli ilişkilerde düzenleyici bir etkisinin bulunabileceği önerilse de (Clarke, 2006), stres ve performans arasındaki ilişkide bu rolünü inceleyen bir araştırma henüz yapılmamıştır. Bireysel (kişilik, yaş, öz etkinlik vb.) ve örgütsel faktörlerin (kontrol yetkisi, eğitim vb.) stresin performans üzerindeki etkisini biçimlendirdiği gibi, farklı ortamlarda da bu etkinin gücünün ve yönünün değişmesi beklenebilir. Johns’a (2006) göre, durumsal faktörlerin belirginliği olarak ifade edilen bağlam kavramı örgütsel tutum ve davranışların anlamını belirlemekte ve işaretleri tersine çevirebilmektedir. Ayrıca Parkes (1986) tarafından bireylerin stres ile baş edebilmesinde durumsal ve çevresel faktörlerin, bireysel faktörler ile etkileşime girdiği gösterilmiştir. Bağlamsal etkiler, sadece stres sonuçları üzerinde değil, güvenlik sonuçları üzerinde de etkili olmaktadır. Örneğin, yüksek bağlılık, katılım ve rekabetçi ortam içeren yüksek performanslı iş sistemlerine sahip ortamların bireysel güvenlik yönelimi ve güvenlik göstergeleri gibi sonuçlarla pozitif ilişkili olduğu bulunmuştur (Zacharatos, Barling ve Iverson, 2005). Bu bağlamsal faktörler, farklı etmenlerin güvenlik performansı üzerindeki etkisinde de rol oynamaktadır. Örneğin daha pozitif ve strateji odaklı örgütsel iklimlerde, örgütlerin hedefleri ile bireylerin bilgi ve performansları uyumlu hale geldiği için, verilen güvenlik eğitiminin güvenlik performansına yansımasının daha kolay olduğu bulunmuştur (Smith-Crowe, Burke ve Landis, 2003). Bu sonuçlar göz önüne alındığında, örgüt ikliminin stres ve performans arasındaki ilişkide önemli bir rol oynaması beklenmektedir. Bir başka deyişle, örgüt ikliminde vurgulanan unsurların ortamdaki bozucu faktörlere daha duyarlı olacağı düşünülmektedir. Bu açıdan bakıldığında, güvenlik ikliminin yüksek olduğu örgütlerde, düşük olduğu örgütlere kıyasla güvenlik performansı daha çok 
önemsendiği için, bu tarz örgütler bireylerin performansını yerine getirirken stresten daha olumsuz etkilenmesine yol açabilir. Ayrıca örgüt iklimi güvenliği vurguladığında bunu bozacak faktörlerin belirginliğinde artış yaşanacağ1, daha olumsuz algılanacağ1 ve böylece olumsuz etkilerinin de kuvvetleneceği beklenmektedir. Bu doğrultuda, mevcut çalışmada iş stresinin güvenlik performansı üzerindeki etkilerinin özellikle güvenlik iklimi tarafindan düzenleneceği öngörülmüştür.

H2: Güvenlik iklimi, iş stresinin a) güvenlik uyumu ve b) güvenlik katılımı ile olan ilişkisinde düzenleyici bir rol oynayacaktır. Yüksek güvenlik iklimine sahip ortamlarda iş stresinin güvenlik uyumu ve katılımı üzerindeki olumsuz etkileri, düşük güvenlik iklimine sahip ortamlara kıyasla daha kuvvetli olacaktır.

\section{YÖNTEM}

\section{Katılımcilar}

Mevcut çalışmanın katılımcıları, İstanbul ve Kocaeli illerinde sağlık sektörü çalışanları arasından ulaşılabilen 121'i (\%73.3) kadın ve 44’ü (\%26.7) erkek 165 gönüllü bireyden oluşmaktadır. Bu bireylerin 69'unun (\%41.8) kamu sektöründeki üç hastanede ve 96'sının (\%58.2) özel sektördeki sekiz hastanede olmak üzere toplamda 11 hastanenin acil, çocuk hastalıkları, kardiyoloji, kadın doğum, yoğun bakım, göz, göğüs hastalıkları gibi çeşitli departmanlarında çalışmakta olduğu tespit edilmiştir. Katılımcıların büyük çoğunluğu hemşire (\%52.1) ve doktorlardan (\%23.6) oluşmakta olup, aralarında teknisyen (\%11.6), fizyoterapist (\%7.9) ve laborantlar (\%4.8) da bulunmaktadır. Kat1lımcıların mevcut kurumlarındaki çalışma süresi bir yıldan 20 yıla kadar değişmektedir ve ortalaması 4.3 yıl olarak belirlenmiştir.

\section{Veri Toplama Araçları}

Bilgilendirilmiş Onam ve Demografik Bilgi Formu. Soru formunun ilk sayfasında çalışmanın amacını açıklayan bilgilendirilmiş onam formu yer almaktadır. $\mathrm{Bu}$ formun devamında cinsiyet, meslek, departman ve kurumda çalışma süresine ilişkin soruların yer aldığı Demografik Bilgi Formu katılımcılara verilmiştir.

İş Stresi Değerlendirme Ölçeği. İş Stresi Bataryası içerisinde yer alan bu ölçek bireylerin çeşitli stresörlere yönelik algılarını değerlendirebilmek amacıyla Özalp Türetgen, Sertel Berk, Başbuğ ve Ünsal (2012) tarafından geliştirilmiştir. Toplamda 43 maddeden oluşan ölçekte beş faktör bulunmaktadır. $\mathrm{Bu}$ faktörler örgütsel norm ve 
uygulamalar, rol ve iş yükü, güvensiz ilişkiler, rol yetersizliği ve fiziksel iş talepleri şeklindedir. Ölçekteki her bir madde için hem sıklık hem de şiddet değerlendirilmektedir. Stresörlerin ne sıklıkta yaşandığına ilişkin değerlendirme "Hiçbir zaman" ile "Her zaman" arasında değişen 5'li skalada, bu stresörün şiddet değerlendirmesi ise "Hiç rahatsız etmiyor" ve "Çok rahatsı ediyor" arasında değişen 10'lu skalada yapılmaktadır. Sıklık ve şiddet skorları çarpılarak o madde için tek bir puan elde edilmektedir. Ölçeğin iç tutarlılık kat sayısı .93 olarak bulunmuştur. Faktörler için elde edilen kat sayıların .66 ile .90 arasında değiştiği görülmüştür. Mevcut araştırmada analizler iş stresi toplam puanı üzerinden yapılmıştır ve ölçeğin kullanılan şekliyle Cronbach alpha katsayısı .95 olarak elde edilmiştir.

Güvenli Davranış Ölçeği. Bu ölçek güvenlik performansı göstergelerinden biri olan güvenli davranışı değerlendirmeye yönelik Neal ve arkadaşları (2000) tarafından geliştirilmiştir. Toplamda altı maddeden oluşan ölçek iki faktöre sahiptir. Güvenlik prosedürlerine uyma ve işlerin güvenli bir şekilde yürütülmesini değerlendiren güvenlik uyumu faktörü ve iş arkadaşlarına yardım etme ve iş yerinde güvenliği artırmaya yönelik çaba sergilemeyi değerlendiren güvenlik katılımı faktörü üçer maddeye sahiptir. Maddeler "1 = Tamamen katılmıyorum" ve "5 = Tamamen katılıorum" arasında değişen 5'li likert tipi skalada puanlanmaktadır. Ölçekten alınan toplam puanın yüksekliği daha güvenli davranışlara işaret etmektedir. Ölçeğin iç tutarlılık kat sayısı güvenlik uyumu faktörü için .94 ve güvenlik katılımı faktörü için .89 olarak bulunmuştur. Ölçeğin Türkçeye uyarlanması Dursun (2011) tarafından yapılmıştır. Uyarlanan bu ölçekte de orijinal ölçekte yer alan iki faktör elde edilmiş, iç tutarlılık katsayıları güvenlik uyumu faktörü için .87 ve güvenlik katılımı faktörü için .85 olarak bulunmuştur. Bu araştırmada ise Cronbach alpha katsayıları sırasıyla .82 ve .92 olarak olarak bulunmuştur.

Güvenlik İklimi Ölçeği. Choudhry, Fang ve Lingard (2009) tarafından geliştirilen 22 maddelik ölçek iki faktöre sahiptir. Bunlardan ilki olumlu ifadelerden oluşan yönetimin ilgisi ve çalışanların katılımı, diğer faktör ise olumsuz ifadelerden oluşan uygun olmayan güvenlik ve iş süreçleri faktörleridir. Bu ölçek Türen, Gökmen, Tokmak ve Bekmezci (2014) tarafından, birbirinin tersi olan maddelerden sadece olumlu olanların korunması yoluyla kısaltılarak Türkçeye uyarlanmıştır. Uyarlama çalışması sağlık sektörü ve elektronik sektöründen iki ayrı örneklemle gerçekleştirilmiştir. Bu çalışma sonucunda elde edilen 14 maddelik ölçekte de yönetimin bakış açısı ve kurallar ve iş arkadaşları ve güvenlik eğitimleri olarak adlandırılan iki faktör elde edilmiştir. Maddeler "1 
= Kesinlikle katılmıyorum" ve "5 = Kesinlikle katıllyorum" arasında değişen 5'li likert tipi skalada puanlanmaktadır. Sağlık sektöründen seçilen ilk örneklemle yürütülen çalışmada elde edilen iç tutarlılık katsayısı .93, elektronik sektöründen seçilen ikinci örneklemle yürütülen çalışmada elde edilen iç tutarlılık katsayısı ise .92 olarak bulunmuştur. Mevcut araştırmada analizler güvenlik iklimi toplam puanı üzerinden yapılmıştır ve ölçeğin tamamı için .92 Cronbach alpha katsayısı saptanmıştır.

\section{İşlem}

Araştırmanın amacı doğrultusunda ölçekler ve bilgilendirilmiş onam formu bir araya getirilerek bir soru formu oluşturulmuştur. Ortak varyans etkisini azaltabilmek maksadıyla ölçeklerin formdaki sıralaması değiştirilerek üç farklı düzende hazırlanmış ve katılımcılara sunulmuştur.

Mevcut çalı̧̧manın verileri 25.04.2019-15.05.2019 tarihleri arasında araştırma için izin alınan hastanelerdeki çalışanlardan toplanmıştır. Ulaşılabilen personele çalışmanın amacı aktarılmış ve katılmaya gönüllü olan personelle çalışma yürütülmüştür. Bu personellere öncelikle ilk sayfasında bilgilendirilmiş onamın yer aldığı soru formları dağıtılmış ve buradaki bilgiler sözel olarak da katılımcılara belirtilmiştir. Katılımcılar kendi çalışma odalarında veya ortak dinlenme odalarında formu doldurmuş ve elden teslim etmişlerdir. Tüm verilerin toplanması yaklaşık üç hafta sürmüştür.

\section{Veri Analizi}

Araştırmanın değişkenleri arasındaki ilişkileri tespit etmek üzere öncelikle korelasyon analizi ve ardından da düzenleyici etkiyi test etmek amacıyla hiyerarşik regresyon analizi yapılmıştır. Vaka sayısının 100'ü aşmasına dayanarak verilerin normal dağıldığı kabul edilmiştir (Blalock, 1979; Tabachnick ve Fidel, 2013). Çoklu doğrusallık ihlali olup olmadığ 1 ise tolerans ve varyans enflasyon faktörü ile değerlendirilmiştir. Genel kriter sınamaları sonrasında hipotezlerin sınanmasına geçilmiştir. Bütün veriler SPSS 22.0 paket programıla analiz edilmiştir.

\section{BULGULAR}

Araştırmada yer alan tüm değişkenler arasındaki ilişkileri incelemek için Pearson Momentler Çarpımı Korelasyon Katsayısı tekniği kullanılmıştır. Sonuçlar Tablo 1'de sunulmuştur. 
Tablo 1. Değişkenler Arasındaki İlişkilere Yönelik Tanımlayııı İstatistikler ve Pearson Korelasyon Katsayıları

\begin{tabular}{lcccccccc}
\hline & Ort. & SS & Min. & Max. & $\mathbf{1}$ & $\mathbf{2}$ & $\mathbf{3}$ & $\mathbf{4}$ \\
\hline 1. İş Stresi & 393.3 & 263.6 & 0 & 1083 & $(.95)$ & $-.59^{* *}$ & $-.38^{* *}$ & $-.24^{* *}$ \\
2. Güvenlik İklimi & 42.78 & 10.6 & 14 & 65 & & $(.92)$ & $.56^{* *}$ & $.38^{* *}$ \\
3. Güvenlik Uyumu & 11.5 & 2.4 & 3 & 15 & & & $(.82)$ & $.52^{* *}$ \\
4. Güvenlik Katılımı & 10.7 & 2.5 & 4 & 15 & & & & $(.92)$ \\
\hline
\end{tabular}

** $p<.01$; tabloda kesişim hücrelerinde parantez içerisinde ilgili değişkenin Cronbach Alpha değeri sunulmuştur.

Tablo 1'de görüldüğü üzere, iş stresinin hem güvenlik uyumu hem de güvenlik kat1lımı ile arasında negatif yönlü ve anlamlı ilişkiler mevcuttur. Bu sonuçlar H1a ve H1b'yi desteklemektedir. Ayrıca güvenlik ikliminin iş stresi ile negatif yönlü ve anlamlı, güvenlik performansı faktörleri ile pozitif yönlü ve anlamlı ilişkilere sahip olduğu görülmektedir. Son olarak, güvenlik uyumu ile güvenlik katılımı arasında da orta düzeyde pozitif yönde anlamlı ilişki saptanmıştır.

Hipotez 2'ye yönelik, iş stresi ile güvenlik performansı alt boyutları arasındaki ilişkide güvenlik ikliminin düzenleyici etkisini incelemek üzere Baron ve Kenny (1986) tarafından önerilen yöntemler dikkate alınarak hiyerarşik regresyon analizi gerçekleştirilmiştir. $\mathrm{Bu}$ analizi kullanabilmek amacıyla yordayıcı ve düzenleyici değişkenler arasında çoklu doğrusal (multicollinearity) ilişki ihlali olup olmadığ 1 incelenmiştir. Analiz sonucunda elde edilen Tolerance ve Varyans Enflasyon Faktörü (VIF) değerleri iş stresi ve güvenlik iklimi arasında çoklu doğrusallık ihlalinin olmadığını göstermektedir (Tolerans $=.658, \mathrm{VIF}=1.520)$. Regresyon analizi öncesinde son olarak yordayıc1 ve düzenleyici değişkenlerin puanı standart $Z$ puanlarına çevrilmiştir. Ayrıca yordayıcı ve düzenleyici değişkenlerin standardize edilmiş değerleri çarpılarak ortak etki değişkeni hesaplanmıştır. Yürütülen hiyerarşik regresyon analizinde ilk modele yordanan değişken olarak güvenlik uyumu, yordayıcı değişken olarak iş stresi birinci adımda, düzenleyici değişken olarak güvenlik iklimi ikinci adımda ve ortak etki değişkeni üçüncü adımda girilmiştir. Bu regresyon analizinin sonuçları Tablo 2'de sunulmuştur.

Tablo 2. İş Stresi ve Güvenlik Uyumu Arasındaki İlişkide Güvenlik İkliminin Düzenleyici Etkisine İlişkin Hiyerarşik Regresyon Analizi Sonuçları

\begin{tabular}{lccccc}
\hline & $\Delta \boldsymbol{R}^{\mathbf{2}}$ & $\boldsymbol{B}$ & $\boldsymbol{\beta}$ & $\boldsymbol{S} \boldsymbol{t}$ & \multicolumn{1}{c}{$\boldsymbol{t}$} \\
\hline İş Stresi & .14 & -.21 & -.09 & .20 & .06 \\
Güvenlik İklimi & .17 & 1.27 & .52 & .20 & $6.39^{* *}$ \\
İş Stresi X Güvenlik İklimi & .00 & -.12 & -.05 & .16 & -.77 \\
\hline
\end{tabular}

$* * p<.001$ 
Tablo 2'de sunulduğu üzere güvenlik uyumundaki değişimin \%14.2'sinin iş stresi tarafından açıklandığı ama bu etkinin anlamlı düzeyde olmadığı saptanmıştır. Güvenlik ikliminin ise modeldeki değişimin \%17.2’sini açıkladığg ve bu etkinin yüksek düzeyde anlamlı olduğu görülmüştür $(p<.001)$. Son adımda ise ortak etkinin güvenlik uyumundaki değişimin \%0.3'ünü açıkladığı ancak bunun da anlamsız düzeyde olduğu görülmektedir. Neticede, iş stresi ile güvenlik uyumu arasındaki ilişkide güvenlik ikliminin düzenleyici rolünü destekleyici bulgulara ulaşılmamıştır. Dolayısıyla, H2a desteklenmemiştir.

H2b’yi sınamak üzere yordanan değişken olarak güvenlik katılımı modele sokularak regresyon analizi tekrarlanmıştır. Bu analizin sonuçları Tablo 3’te sunulmuştur.

Tablo 3. İş Stresi ve Güvenlik Katılımı Arasındaki İlişkide Güvenlik İkliminin Düzenleyici Etkisine İlişkin Hiyerarşik Regresyon Analizi Sonuçları

\begin{tabular}{|c|c|c|c|c|c|}
\hline & $\Delta R^{2}$ & $B$ & $\beta$ & $S E$ & $t$ \\
\hline$\overline{\text { İş Stresi }}$ & .06 & -.14 & -.06 & .22 & -.62 \\
\hline Güvenlik İklimi & .09 & 1.03 & .42 & .22 & $4.67^{* *}$ \\
\hline İș Stresi X Güvenlik İklimi & .04 & -.49 & -.21 & .17 & $-2.83^{*}$ \\
\hline
\end{tabular}

${ }^{*} p<.01,{ }^{* *} p<.001$

Tablo 3'te görüldüğü üzere güvenlik katılımındaki değişimin \%5.7'sinin iş stresi tarafından açıklandığı ancak bu katkının anlamlı olmadığı görülmektedir. Güvenlik ikliminin ise modeldeki değişimin \%9'unu açıkladığı ve bu katkının yüksek düzeyde anlamlı olduğu bulunmuştur $(p<.001)$. Son adımda modele eklenen ortak etki ise güvenlik katılımındaki değişimin \%4'ünü açıklamaktadır ve bu katkının da orta düzeyde anlamlı olduğu görülmektedir $(p<.01)$. Bu sonuçlar, iş stresi ile güvenlik katılımı arasındaki ilişkide güvenlik ikliminin düzenleyici rolünü göstermektedir. Bu etkinin bulunmasının ardından, etkinin yönünü belirleyebilmek amacıyla slope analizi gerçekleştirilmiş ve elde edilen grafik Şekil 1'de sunulmuştur. 


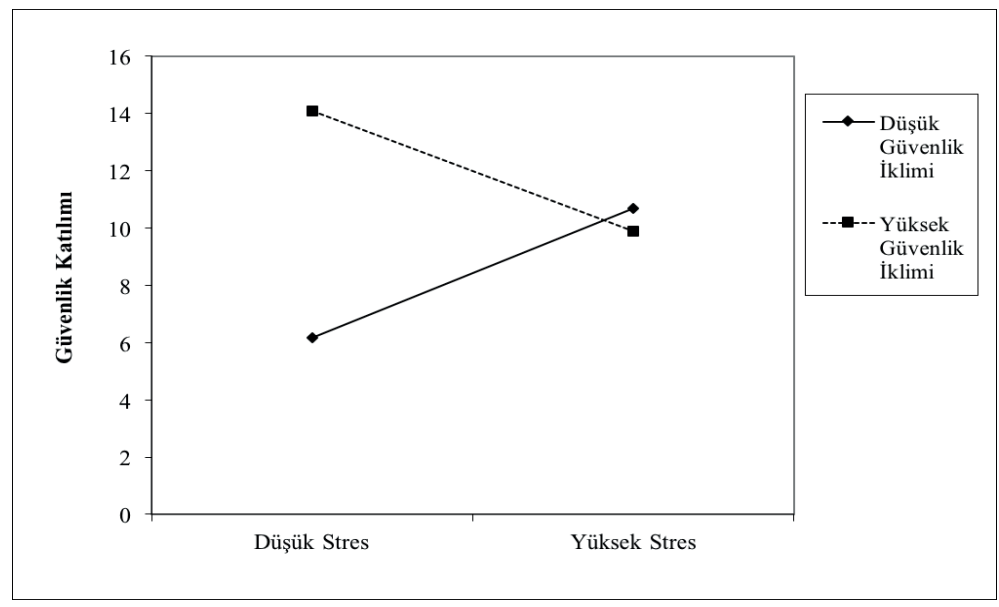

Şekil 1. Güvenlik Katılımı Üzerinde İş Stresi ve Güvenlik İkliminin Etkileşimi

Şekil 1'de görüldüğü üzere, farklı güvenlik iklimi düzeylerine sahip ortamlarda iş stresinin güvenlik katılımı üzerindeki etkisi de farklılaşmaktadır. Öncelikle stres düzeyi düşük olduğunda, yüksek güvenlik iklimine sahip ortamlarda güvenlik katılımının da daha yüksek olduğu görülmektedir. Ancak güvenlik ikliminin yüksek olduğu ortamlar, düşük olduğu ortamlara kıyasla iş stresindeki artıştan daha olumsuz etkilenmektedir. $\mathrm{Bu}$ ortamlarda stres düzeyinin artması güvenlik katılımını anlamlı düzeyde azaltmaktadır ( simple slope $=-1.148, t=-2.686, p<.05$ ). Güvenlik iklimi düşük ortamlarda ise stres düzeyindeki artış beraberinde güvenlik katılımını da anlamlı düzeyde artırmaktadır (simple slope $=1.175, t=2.501, p<.05$ ). Bu sonuçlar, H2b'yi desteklemektedir.

\section{TARTIŞMA}

Mevcut araştırmada, sağlık sektöründe çalışanların iş yerinde algıladıkları stres düzeyinin güvenlik davranışları üzerindeki etkisi ve bu etkide güvenlik iklimi algısının düzenleyici rolünün incelenmesi amaçlanmıştır. Araştırmanın neticesinde, beklenildiği gibi iş stresi ile güvenlik uyumu ve katılımı arasında negatif yönlü ilişkiler tespit edilmiştir. Ayrıca, iş stresi ile güvenlik katılımı arasındaki ilişkide güvenlik ikliminin düzenleyici olduğu görülmüştür.

Araştırmanın ilk hipotezi doğrultusunda yapılan analiz sonucunda bireylerin algıladıkları stres düzeyi arttıkça güvenlik uyumu ve katılımının azaldığı görülmüştür. Alan yazında daha önce yürütülen çalışmalarda iş yerinde algılanan çeşitli stresörlerin üret- 
kenliğe yönelik görev performansını (örn., Wu, 2011; Yozgat, Yurtkoru ve Bilginoğlu, 2013) ve bağlamsal performansı (örn., Chen, 2009; Nisar ve Rasheed, 2019) olumsuz etkilediği bulunmuştur. Bu araştırmada ise iş stresinin güvenlik performansının hem göreve yönelik hem bağlamsal yönü ile arasında negatif yönlü ilişkilere sahip olduğu ortaya konulmuştur. Yapılan çalışmalarda görev ve bağlamsal performansın daha çok örgütler açısından önemine değinilirken (örn., Podsakoff ve MacKenzie, 1997), güvenlik performansının doğrudan bireylerin sağlı̆̆ı üzerinde etkili olan ve örgütlere büyük maliyetler yaratan yaralanma ve kaza gibi güvenlik çıktıları üzerinde etkili olduğu bulunmuştur (örn., Christian, Bradley, Wallace ve Burke, 2009). Bu nedenle ortaya konulan iş stresi ve güvenlik performansı ilişkisi, örgütler kadar çalışanların kendisi ve hastalar açısından da önem arz etmektedir. Mevcut araştırmada, iş stresinin ölçümünde hem görev performansını zorlaştırabilecek rol ve iş yükü faktörü hem de bağlamsal performans ile ilişkili olabilecek güvensiz ilişkiler ve örgütsel uygulamalar gibi çeşitli stresörler ele alınmıştır. İşs stresinin bu şekilde değerlendirilmesi, güvenlik performansının farklı yönleri ile ilişkili bulunmasını anlaşııı kılmaktadır. Bu sonuçlar göz önüne alındığında, çalışanlardan yüksek performans beklentisi içerisinde olan örgütlerde bireylerin kapasiteleri doğrultusunda iş yükü dağılımının yapılmasına özen gösterilmesi, benimsenen örgütsel değerler aracıllı̆ıyla adalet algısının oluşturulması ve çalışanların rekabetten ziyade iş birliğine yönlendirilmesi önem kazanmaktadır.

Araştırmada oluşturulan ikinci hipoteze yönelik gerçekleştirilen analizler, iş stresinin güvenlik uyumu üzerindeki etkisinde güvenlik ikliminin düzenleyici bir rol oynamadığını göstermektedir. Bu sonuçtan yola çıkarak, güvenlik açısından çalışanlardan beklenen görev performansının iklim düzeyinden bağımsız olarak iş stresi ile ilişkili olduğu söylenebilir. Diğer yandan, stresin bağlamsal performans üzerindeki etkilerinin ise güvenlik iklimine bağlı olarak değiştiği anlaşılmaktadır. Düşük güvenlik iklimine sahip ortamlarda, çalışanlar stres düzeyinin artmasına reaksiyon göstererek daha fazla güvenlik katılımı sergilemektedir. Fakat yüksek güvenlik iklimine sahip olunduğunda, çal1şanlar strese dayanıksızlık göstermekte ve güvenlik katılımlarında azalma yaşanmaktadır. Bu doğrultuda, kimi sektörlerde güvenlik ikliminin yüksek olması teşvik edilse de bu iklimin beraberinde getirdiği bazı zorlu durumların olduğu ifade edilebilir. Güvenlik ikliminin sağlanmasının güvenlik performansını artırmasına karşın (Rahlin, Mustafa ve Majid, 2016) bu olumlu etkilerin korunması için iş yerindeki stres kaynaklarının da düzenlenmesi gerekmektedir. Aksi takdirde bu faktörler daha çok bozucu etkilere yol aç- 
makta ve yüksek güvenlik ikliminin sağladığı faydalar tersine dönmektedir. Örgüt ikliminin sağladığı çeşitli faydalar ortaya konulmuş olsa da (Brown ve Leigh, 1996; Fu ve Deshpande, 2014; Neal ve ark., 2000), stres faktörlerinin algılanması üzerindeki yan etkileri ilk defa bu araştırmada ortaya konulmuştur. $\mathrm{Bu}$ yan etkilerin giderilmesi adına güvenlik iklimini önemsemekle birlikte çalışma koşullarının düzenlenmesi, dayanışma ve güven kültürünün teşvik edilmesi gerekmektedir.

Daha önce duygusal zeka (Lu ve Kuo, 2016) ve öz benlik değerlendirmesi (Yuan ve ark., 2014) gibi bireysel değişkenlerin güvenlik performansı açısından bireyleri strese karşı daha korunaklı kıldığı gösterilmiştir. Mevcut çalışmada ise güvenlik ikliminin düzenleyici rol üstlendiği, bireyleri stresin güvenlik performansının bağlamsal yönü üzerindeki etkilerine karşı daha dayanıksız kıldığı görülmüştür. İleride yapılacak çalışmalarda, bireyler açısından dezavantaj yaratan kişisel özelliklerin ve çalışanları korunaklı kılacak örgütsel özelliklerin belirlenmesine ihtiyaç duyulmaktadır.

$\mathrm{Bu}$ sonuçlar alan yazında bugüne kadar elde edilen tutarsız bulgulara yönelik olası bir açıklama sağlamaktadır. Aynı sektörde elde edilen sonuçların farklılaşması dayanıklılık ve duygusal zeka gibi bazı bireysel faktörlere dayandırılmışken (Westman, 1990; Yozgat ve ark., 2013), mevcut sonuçlar göz önünde bulundurularak farklı çevrelerde yürütülen araştırmalarda farklı sonuçlar elde edilmesi de ortamsal faktörlere dayandırılabilir. Bu sonuç, bireylerin stres ile baş etmelerinin çevresel faktörlerden etkilenebileceği önermesi ile uyumludur (Parkes, 1986). Güvenlik ikliminin bu faktörlerden biri olduğunun gösterilmesi sonrasında, başka hangi ortamsal faktörlerin bu süreçte etkili olabileceğinin düşünülmesi ve araştırılması gerekmektedir. Ayrıca mevcut çalışmada ortaya konulan bu modelin alan yazında daha önce sınanmamış olması nedeniyle farklı sektörlerde de sınanması bulguların genellenebilirliği açısından faydalı olacaktır.

Mevcut çalışmanın sonuçları değerlendirilirken, ortamsal bir faktör olarak sektör değişkeni göz önünde bulundurulmalıdır. Araştırmanın en stresli sektörler arasında yer alan sağlık sektöründe yürütülmüş olması sonuçların bu şekilde elde edilmesinde etkili olmuş olabilir. Çünkü stres, düzeyinin yüksekliğine bağlı olarak performans üzerinde yapıc1 (eustress) ve y1k1c1 (distress) etkilere sahip olabilmektedir (Cranwell-Ward ve Abbey, 2005). Mevcut sektörde algılanan stres zaten yüksek olduğundan, bu düzeyin daha da artması performans üzerindeki etkilerinin giderek olumsuzlaşmasına neden olmuş olabilir. Ancak düşük seviyede iş stresine sahip olan ortamlarda, stres düzeyindeki artışın performans üzerinde olumlu etkileri de görülebilir. 
Mevcut araştırmada, güvenlik performansının sadece bireylerin öz bildirimine daya11 olarak elde edilmesi temel kısıtl1lıklardan bir tanesidir. Alan yazında güvenlik performansı öz bildirime dayalı elde edildiği gibi objektif verilerle de ölçülmektedir (Mearns ve ark., 2001; Smith, Cohen, Cohen ve Cleveland, 1978; Tomas, Melia ve Oliver, 1999; Zohar, 2000). Ölçümler esnasında subjektif değerlendirmelerin objektif göstergelerle desteklenmesi daha zengin veriler sunacaktır. Ayrıca verilerin tek bir zaman diliminde toplanmış olması iş stresinin uzun süreli olası etkilerini görmemizi de engelleyebilmektedir. Gelecekte yürütülecek boylamsal çalışmalarla beraber iş stresinin uzun süreli etkileri gözlemlenebilecektir. Son olarak bu araştırmada sağlık sektöründeki durumun incelenmesi hedeflenmiş ve araştırma buna uygun kurumlarda yürütülmüştür. Güvenlik ikliminin yüksek olması beklenen havacılık gibi diğer sektörlerde ve bu sektörlerde olduğu kadar güvenlik konusu üzerinde durulmayan diğer sektörlerde de iş stresinin etkilerinin araştırılması daha detaylı karşılaştırmalar yapılmasını sağlayacaktır.

\footnotetext{
Hakem Değerlendirmesi: Dış bağımsız.

Çıkar Çatışması: Yazarlar çıkar çatışması bildirmemiştir.

Finansal Destek: Yazarlar bu çalışma için finansal destek almadığını beyan etmiştir.

Peer-review: Externally peer-reviewed.

Conflict of Interest: The authors have no conflict of interest to declare.

Grant Support: The authors declared that this study has received no financial support.
}

\section{Kaynakça/References}

Ajayi, S. (2018). Effect of stress on employee performance and job satisfaction: A case study of Nigerian banking industry (Çevrimiçi), 27 Eylül 2019, https://ssrn.com/abstract=3160620

Australian Transport Safety Bureau (2004). Aviation Safety Survey - Safety Climate Factors (Çevrimiçi), 27 Eylül 2019, https://www.atsb.gov.au/media/36879/Safety_climate_factors.pdf.

Baron, R. M. ve Kenny, D. A. (1986). The moderator-mediator variable distinction in social psychological research: Conceptual, strategic, and statistical considerations. Journal of Personality and Social Psychology, 51(6), 1173-1182.

Blalock, H. M. (1979). Social statistics. Revised second edition. New York: McGraw-Hill.

Borman, W. C. ve Motowidlo, S. M. (1993). Expanding the criterion domain to include elements of contextual performance. N. Schmitt ve W. C. Borman (Ed.), Personnel selection in organizations içinde (s. 71-98), San Francisco: Jossey-Bass.

Bowers, C. A., Weaver, J. L. ve Morgan, B. B. (1996). Moderating the performance effects of stressors. J.E. Driskell ve E. Salas (Ed.), Stress and human performance içinde (s. 163-192), New Jersey: Lawrence Erlbaum Associates. 
Brown, S. P. ve Leigh, T. W. (1996). A new look at psychological climate and its relationship to job involvement, effort, and performance. Journal of Applied Psychology, 81(4), 358-368. doi; 00219010/96/S3.00

Burke, M. J., Sarpy, S. A., Tesluk, P. E. ve Smith-Crowe, K. (2002). General safety performance: A test of a grounded theoretical model. Personnel Psychology, 55(2), 429-457. doi; 10.1037/00332909.88.1.82

Chen, Y. F. (2009). Job stress and performance: A study of police officers in central Taiwan. Social Behavior and Personality: An International Journal, 37(10), 1341-1356. doi; 10.2224/sbp.2009.37.10.1341

Choudhry, R. M., Fang, D. ve Lingard, H. (2009). Measuring safety climate of a construction company. Journal of Construction Engineering and Management, 135(9), 890-899. doi; 10.1061/ (ASCE)CO.1943-7862.0000063

Christian, M. S., Bradley, J. C., Wallace, J. C. ve Burke, M. J. (2009). Workplace safety: A metaanalysis of the roles of person and situation factors. Journal of Applied Psychology, 94(5), 11031127. doi; $10.1037 / \mathrm{a} 0016172$

Clarke, S. (2006). The relationship between safety climate and safety performance: A meta-analytic review. Journal of Occupational Health Psychology, 11(4), 315-327. doi; 10.1037/1076-8998.11.4.315

Clarke, S. (2010). An integrative model of safety climate: Linking psychological climate and work attitudes to individual safety outcomes using meta-analysis. Journal of Occupational and Organizational Psychology, 83(3), 553-578. doi; 10.1348/096317909X452122

Clarke, S. (2013). Safety leadership: A meta-analytic review of transformational and transactional leadership styles as antecedents of safety behaviours. Journal of Occupational and Organizational Psychology, 86(1), 22-49. doi; 10.1111/j.2044-8325.2012.02064.x

Cranwell-Ward, J. ve Abbey, A. (2005). Organizational stress. New York: Palgrave Macmillan.

Dedobbeleer, N. ve Béland, F. (1991). A safety climate measure for construction sites. Journal of Safety Research, 22(2), 97-103. doi; 10.1016/0022-4375(91)90017-P

Dester, W. S. ve Blockley, D. I. (1995). Safety—behaviour and culture in construction. Engineering, Construction and Architectural Management, 2(1), 17-26. doi; 10.1108/eb021000

Dollard, M. F. ve McTernan, W. (2011). Psychosocial safety climate: A multilevel theory of work stress in the health and community service sector. Epidemiology and Psychiatric Sciences, 20(4), 287293. doi; $10.1017 / \mathrm{S} 2045796011000588$

Dursun, S. (2011). Güvenlik kültürünün güvenlik performansı üzerine etkisine yönelik bir uygulama. (Yayımlanmamış Doktora Tezi). Uludağ Üniversitesi/Sosyal Bilimler Enstitüsü, Bursa.

El-nagar, R., Hosny, H. ve Askar, H. S. (2015). Development of a safety performance index for construction projects in Egypt. American Journal of Civil Engineering and Architecture, 3(5), 182192. doi; 10.12691/ajcea-3-5-5

Enshassi, A., El-Rayyes, Y. ve Alkilani, S. (2015). Job stress, job burnout and safety performance in the Palestinian construction industry. Journal of Financial Management of Property and Construction, 20(2), 170-187. doi; 10.1108/JFMPC-01-2015-0004

Flin, R., Mearns, K., O’Connor, P. ve Bryden, R. (2000). Measuring safety climate: Identifying the common features. Safety Science, 34(1-3), 177-192. doi; 10.1016/s0925-7535(00)00012-6

Foster, P. ve Hoult, S. (2013). The safety journey: Using a safety maturity model for safety planning and assurance in the UK coal mining industry. Minerals, 3(1), 59-72. doi; 10.3390/min3010059

Fu, W. ve Deshpande, S. P. (2014). The impact of caring climate, job satisfaction, and organizational commitment on job performance of employees in a China's insurance company. Journal of Business Ethics, 124(2), 339-349. doi; 10.1007/s10551-013-1876-y 
Gibb, A. G., Haslam, R., Gyi, D. E., Hide, S. ve Duff, R. (2006). What causes accidents? Civil Engineering, 159(2), 46-50.

Gilboa, S., Shirom, A., Fried, Y. ve Cooper, C. (2008). A meta-analysis of work demand stressors and job performance: Examining main and moderating effects. Personnel Psychology, 61(2), 227-271. doi; 10.1111/j.1744-6570.2008.00113.x

Gill, G. K., Shergill ve G. S. (2004). Perceptions of safety management and safety culture in the aviation industry in New Zealand. Journal of Air Transport Management, 10(4), 231-237. doi; 10.1016/j. jairtraman.2004.02.002

Goh, J., Pfeffer, J. ve Zenios, S. A. (2016). The relationship between workplace stressors and mortality and health costs in the United States. Management Science, 62(2), 608-628. doi; 10.1287/ mnsc.2014.2115

Griffin, M. A. ve Curcuruto, M. (2016). Safety climate in organizations. Annual Review of Organizational Psychology and Organizational Behavior, 3, 191-212. doi; 10.1146/annurevorgpsych-041015-062414

Hart, P. M. ve Cooper, C. L. (2001). Occupational stress: Toward a more integrated framework. N. Anderson, D.S. Ones, H.K. Sinangil ve C. Viswesvaran (Ed.), Handbook of industrial, work and organizational psychology içinde (s. 93-114). London: Sage.

Hofmann, D. A. ve Stetzer, A. (1996). A cross-level investigation of factors influencing unsafe behaviors and accidents. Personnel Psychology, 49(2), 307-339. doi; 10.1111/j.1744-6570.1996.tb01802.x

Jamal, M. (2007). Job stress and job performance controversy revisited: An empirical examination in two countries. International Journal of Stress Management, 14(2), 175. doi; 10.1037/10725245.14.2.175

Johns, G. (2006). The essential impact of context on organizational behavior. Academy of Management Review, 31(2), 386-408. doi; 10.5465/amr.2006.20208687

Kavanagh, J. (2005). Stress and performance: A review of the literature and its applicability to the military. Santa Monica CA: Rand Corp.

LePine, J. A., Podsakoff, N. P. ve LePine, M. A. (2005). A meta-analytic test of the challenge stressorhindrance stressor framework: An explanation for inconsistent relationships among stressors and performance. Academy of Management Journal, 48(5), 764-775. doi; 10.5465/amj.2005.18803921

Leung, M. Y., Chan, I. Y. S. ve Yu, J. (2012). Preventing construction worker injury incidents through the management of personal stress and organizational stressors. Accident Analysis \& Prevention, 48, 156-166. doi; 10.1016/j.aap.2011.03.017

Liu, H., Song, G. ve Wang, D. (2011). The influence of self-efficacy on flight dispatchers'stressor-strain relationships. Social Behavior and Personality: An International Journal, 39(6), 839-850.

Lu, C. S. ve Kuo, S. Y. (2016). The effect of job stress on self-reported safety behaviour in container terminal operations: The moderating role of emotional intelligence. Transportation Research Part F: Traffic Psychology and Behaviour, 37, 10-26. doi; 10.1016/j.trf.2015.12.008

Mearns, K., Whitaker, S. M. ve Flin, R. (2001). Benchmarking safety climate in hazardous environments: A longitudinal, interorganizational approach. Risk Analysis, 21(4), 771-786. doi; 10.1111/02724332.214149

Muse, L. A., Harris, S. G. ve Feild, H. S. (2003). Has the inverted-u theory of stress and job performance had a fair test?. Human Performance, 16(4), 349-364. doi; 10.1207/S15327043HUP1604_2

Nahrgang, J. D., Morgeson, F. P. ve Hofmann, D. A. (2011). Safety at work: A meta-analytic investigation of the link between job demands, job resources, burnout, engagement, and safety outcomes. Journal of Applied Psychology, 96(1), 71-94. doi; 10.1037/a0021484 
Neal, A., Griffin ve M. A. (2006). A study of the lagged relationships among safety climate, safety motivation, safety behavior, and accidents at the individual and group levels. Journal of Applied Psychology, 91(4), 946-953. doi; 10.1037/0021-9010.91.4.946

Neal, A., Griffin, M. A. ve Hart, P. M. (2000). The impact of organizational climate on safety climate and individual behavior. Safety Science, 34(1-3), 99-109. doi; 10.1016/S0925-7535(00)00008-4

Nisar, S. K. ve Rasheed, M. I. (2019). Stress and performance: Investigating relationship between occupational stress, career satisfaction, and job performance of police employees. Journal of Public Affairs, 1-9. doi; 10.1002/pa.1986

Okutan, M. ve Tengilimoğlu, D. (2002). İş ortamında stres ve stresle başa çıkma yöntemleri: Bir alan uygulamas1. Gazi Üniversitesi İktisadi ve İdari Bilimler Fakültesi Dergisi, 4(3), 15-42.

Ostroff, C., Kinicki, A. J. ve Muhammad, R. S. (2013). Organizational culture and climate. I. B. Weiner, N. W. Schmitt ve S. Highhouse (Ed.), Handbook of psychology: Industrial and organizational psychology içinde (s. 643-676). New York: Wiley.

Özalp Türetgen, İ., Sertel Berk, Ö., Başbuğ, G. ve Ünsal, P. (2012). The development of the job stressor appraisal scale as part of the job stress battery. European Journal of Psychological Assessment, 28, 147-153. doi; 10.1027/1015-5759/a000103

Parkes, K. R. (1986). Coping in stressful episodes: The role of individual differences, environmental factors, and situational characteristics. Journal of Personality and Social Psychology, 51(6), 12771292. doi; 10.1037/0022-3514.51.6.1277

Podsakoff, P. M. ve MacKenzie, S. B. (1997). Impact of organizational citizenship behavior on organizational performance: Areview and suggestion for future research. Human Performance, 10(2), 133-151. doi; 10.1207/s15327043hup1002_5

Probst, T. M. ve Brubaker, T. L. (2001). The effects of job insecurity on employee safety outcomes: Cross-sectional and longitudinal explorations. Journal of Occupational Health Psychology, 6(2), 139-159. doi; 10.1037/1076-8998.6.2.139

Rahlin, N. A., Mustafa, M. ve Majid, A. H. A. (2016). The impact of psychological safety climate on individual safety performance in the Malaysian manufacturing small enterprise: the role of psychological factor and psychological work ownership. World Journal of Management and Behavioral Studies, 4(1), 8-19. doi; 10.5829/idosi.wjmbs.2016.4.1.1324

Sawacha, E., Naoum, S. ve Fong, D. (1999). Factors affecting safety performance on construction sites. International Journal of Project Management, 17(5), 309-315. doi; 10.1016/S02637863(98)00042-8

Schein, E. H. (2000). Sense and nonsense about culture and climate. N. M. Ashkanasy, C. P. M. Wilderom ve M. F. Peterson (Ed.), Handbook of organizational culture \& climate içinde (s. 23 30). Thousand Oaks, CA: Sage.

Schneider, B. (2000). The psychological life of organizations. N. M. Ashkanasy, C. P. M. Wilderom ve M. F. Peterson (Ed.), Handbook of organizational culture \& climate içinde (s. 17-21). Thousand Oaks, CA: Sage.

Schneider, B., Ehrhart, M. G. ve Macey, W. H. (2011). Organizational climate research: achievements and the road ahead. N. M. Ashkanasy, C. E. P. Wilderom ve M. F. Peterson (Ed.), The handbook of culture and climate içinde (s. 29-49). Thousand Oaks, CA: Sage.

Schreurs, B. H., Hetty van Emmerik, I. J., Günter, H. ve Germeys, F. (2012). A weekly diary study on the buffering role of social support in the relationship between job insecurity and employee performance. Human Resource Management, 51(2), 259-279. doi; 10.1002/hrm.21465 
Shirom, A., Shechter Gilboa, S., Fried ve Y. Cooper, C. L. (2008). Gender, age and tenure as moderators of work-related stressors' relationships with job performance: A meta-analysis. Human Relations, 61(10), 1371-1398. doi; 10.1177/0018726708095708

Silva, S., Lima, M. L. ve Baptista, C. (2004). OSCI: An organisational and safety climate inventory. Safety Science, 42(3), 205-220. doi; 10.1016/S0925-7535(03)00043-2

Singer, S., Lin, S., Falwell, A., Gaba, D. ve Baker, L. (2009). Relationship of safety climate and safety performance in hospitals. Health Services Research, 44, 399-421. doi; 10.1111/j.14756773.2008.00918.x

Singh, V., Sharma, S. K., Chadha, I. ve Singh, T. (2019). Investigating the moderating effects of multi group on safety performance: The case of civil aviation. Case Studies on Transport Policy, 7(2), 477-488. doi; 10.1016/j.cstp.2019.01.002

Siu, O. L., Phillips, D. R. ve Leung, T. W. (2003). Age differences in safety attitudes and safety performance in Hong Kong construction workers. Journal of Safety Research, 34(2), 199-205. doi; 10.1016/S0022-4375(02)00072-5

Siu, O. L., Phillips, D. R. ve Leung, T. W. (2004). Safety climate and safety performance among construction workers in Hong Kong: The role of psychological strains as mediators. Accident Analysis \& Prevention, 36(3), 359-366. doi; 10.1016/S0001-4575(03)00016-2

Smith, M., Cohen, H., Cohen, A. ve Cleveland, R. (1978). Characteristics of successful safety programs. Journal of Safety Research, 10(1), 5-15.

Smith-Crowe, K., Burke, M.J. ve Landis, R.S. (2003). Organizational climate as a moderator of safety knowledge-safety performance relationships. Journal of Organizational Behavior: The International Journal of Industrial, Occupational and Organizational Psychology and Behavior, 24(7), 861-876. doi; 10.1002/job.217

Tabachnick, B. G. ve Fidell, L. S. (2013). Using multivariate statistics (Vol. 6). Boston, MA: Pearson.

Tomás, J. M., Melia, J. L. ve Oliver, A. (1999). A cross-validation of a structural equation model of accidents: Organizational and psychological variables as predictors of work safety. Work \& Stress, 13(1), 49-58. doi; 10.1080/026783799296183

Türen, U., Gökmen, Y., Tokmak, İ. ve Bekmezci, M. (2014). Güvenlik İklimi Ölçeği’nin geçerlilik ve güvenirlilik çalışması. Süleyman Demirel Üniversitesi Íktisadi ve İdari Bilimler Fakültesi Dergisi, 19(4), 171-190.

Westman, M. (1990). The relationship between stress and performance: The moderating effect of hardiness. Human Performance, 3(3), 141-155. doi; 10.1207/s15327043hup0303_1

Williamson, A. M., Feyer, A. M., Cairns, D. ve Biancotti, D. (1997). The development of a measure of safety climate: The role of safety perceptions and attitudes. Safety Science, 25(1-3), 15-27. doi; 10.1016/S0925-7535(97)00020-9

Wu, T. C., Chen, C. H. ve Li, C. C. (2008). A correlation among safety leadership, safety climate and safety performance. Journal of Loss Prevention in the Process Industries, 21(3), 307-318. doi; 10.1016/j.jlp.2007.11.001

$\mathrm{Wu}$, Y. C. (2011). Job stress and job performance among employees in the Taiwanese finance sector: The role of emotional intelligence. Social Behavior and Personality: An International Journal, 39(1), 21-31. doi; 10.2224/sbp.2011.39.1.21

Yerkes, R. M. ve Dodson, J. D. (1908). The relation of strength of stimulus to rapidity of habitformation. Journal of Comparative Neurology and Psychology, 18(5), 459-482. doi; 10.1002/ cne. 920180503 
Yozgat, U., Yurtkoru, S. ve Bilginoğlu, E. (2013). Job stress and job performance among employees in public sector in İstanbul: Examining the moderating role of emotional intelligence. Procedia-Social and Behavioral Sciences, 75, 518-524. doi; 10.1016/j.sbspro.2013.04.056

Yuan, Z., Li, Y. ve Lin, J. (2014). Linking challenge and hindrance stress to safety performance: The moderating effect of core self-evaluation. Personality and Individual Differences, 68, 154-159. doi; 10.1016/j.paid.2014.04.025

Yule, S. (2003). Senior management influence on safety performance in the UK and US energy sectors (Yayımlanmamış doktora tezi). University of Aberdeen, Scotland.

Zacharatos, A., Barling, J. ve Iverson, R. D. (2005). High-performance work systems and occupational safety. Journal of Applied Psychology, 90(1), 77-93. doi; 10.1037/0021-9010.90.1.77

Zohar, D. (1980). Safety climate in industrial organizations: Theoretical and applied implications. Journal of Applied Psychology, 65(1), 96-102. doi; 10.1037/0021-9010.65.1.96

Zohar, D. (2000). A group-level model of safety climate: Testing the effect of group climate on microaccidents in manufacturing jobs. Journal of Applied Psychology, 85(4), 587-596. doi; $10.1037 / 0021-9010.85 .4 .587$ 
